\title{
Clinical outcomes comparison of 10 years versus 5 years of adjuvant endocrine therapy in patients with early breast cancer
}

\author{
$\mathrm{Li} \mathrm{Li}^{1 \dagger}$, Bingmei Chang ${ }^{1,2+}$, Xiaoyue Jiang ${ }^{1}$, Xueke Fan ${ }^{3}$, Yingrui $\mathrm{Li}^{4}$, Teng $\mathrm{Li}^{1}$, Shanshan $\mathrm{Wu}^{5}$, Jun Zhang ${ }^{6}$,
} Seyed Kariminia ${ }^{7}$ and Qin $\mathrm{Li}^{1^{*}}$ (D)

\begin{abstract}
Background: Adjuvant endocrine therapy undoubtedly prolongs the time to recurrence for patients with hormone-positive early breast cancer. Extended endocrine therapy to 10 years or longer has been expected to bring a greater clinical advantage. However, the related research conclusions are controversial.

Methods: Tamoxifen (TAM), Aromatase Inhibitor (AI), Exemestane, letrozole (LET) and anastrozole were used as key words in the literature search. After the patients completed 5 years of adjuvant endocrine treatment, they were allocated to continue endocrine treatment for 5 years or receive placebo/observation for 5 years. Disease-free survival (DFS) and overall survival (OS) were the end points. Systematic assessment was performed using Stata 12.0.

Results: Twelve trials including 30,848 cases were involved. The overall analysis demonstrated that extended endocrine therapy to 10 years significantly prolonged DFS compared with 5 years of endocrine therapy [hazard ratio $(H R)=0.84,95 \% \mathrm{Cl}: 0.73-0.97]$. Subgroup analysis showed that DFS was significant prolonged with TAM $5 y-\mathrm{Al}$ $5 y$ treatment versus TAM $5 y$ treatment and with (Al and/or TAM) $5 y$ - LET $5 y$ treatment versus (Al and/or TAM) $5 y$ treatment $[(H R=0.61,95 \% \mathrm{Cl}: 0.50-0.76)$ and $(H R=0.81,95 \% \mathrm{Cl}: 0.71-0.93)$, respectively]. However, no significant difference was found in the DFS with TAM 5y - TAM 5y treatment versus TAM 5y treatment (HR=0.97, 95\% Cl: 0 . 81-1.17). Overall and subgroup analysis did not demonstrate an OS benefit of therapy extended to 10 years. A DFS benefit of extended endocrine therapy to 10 years was verified in the lymph node-positive subgroup, postmenopausal subgroup and ER+ and/or PR+ subgroup ( $\mathrm{HR}=058,95 \% \mathrm{Cl}: 0.45-0.75 ; \mathrm{HR}=0.70,95 \% \mathrm{Cl}: 0.58-0.80$; $\mathrm{HR}=0.80,95 \% \mathrm{Cl}:$ 0.67-0.96).

Conclusions: An extended 10 years of endocrine treatment yields a DFS benefit for patients with early breast cancer; (Al and/or TAM) 5y - Al 5y treatment is the optimal choice. ER+ and/or PR+, postmenopausal and lymph node-positive patients are the most suitable groups.
\end{abstract}

Keywords: Breast cancer, Extended endocrine treatment, Tamoxifen, Aromatase inhibitor, Disease-free survival

\section{Background}

For patients with hormone-positive early breast cancer, adjuvant endocrine therapy undoubtedly prolongs the time to recurrence [1-3]. Moreover, 5 years of adjuvant endocrine treatment has been verified to be more effective than 1-2 years of treatment [3]. However, the recurrence

\footnotetext{
* Correspondence: oncologistinbj@163.com

${ }^{+} \mathrm{Li}$ Li and Bingmei Chang contributed equally to this work.

'Department of Oncology, Beijing Friendship Hospital, Capital Medical University, Beijing 100050, China

Full list of author information is available at the end of the article
}

rate of patients receiving tamoxifen (TAM) increases from $15 \%$ at 5 years to $33 \%$ at 15 years, and cancer mortality increases from $8.3 \%$ at 5 years to $26 \%$ at 15 years [3]. To control the increased recurrence rate and mortality rate even after receiving 5-year adjuvant endocrine treatment, extended endocrine therapy to 10 years or longer is expected to bring more clinical advantage. However, the research conclusions are controversial.

Both TAM and aromatase inhibitors (AIs) are used as extended adjuvant endocrine regimens. In MA.17, NSABP-B42, MA-17R trials, the prolonged application 
of AI to 10 years significantly reduced the recurrence risk after 5 years of adjuvant TAM and/or AI treatment [4-6]. However, in the NSABP-B33 trial, prolonged exemestane (EMT) for 5 years did not significantly decrease the recurrence compared with placebo [7]. In the IDEAL (S1-04) trial, prolonged letrozole (LET) for 5 years also did not prolong the disease-free survival (DFS) compared with prolonged LET for 2.5 years [8]. An extended 10 years of adjuvant TAM compared with 5 years TAM showed mixed results. The ATLAS, aTTom, E4181/ E5181 trials showed significant recurrence reduction by 10 years of TAM treatment compared with 5 years of TAM treatment; however, the Scottish trial demonstrated no benefit of extended adjuvant TAM [9-12]. Additionally, the National Surgical Adjuvant Breast and Bowel Project (NSABP) B-14 reported extended TAM by more than 5 years led to a shorter DFS. Furthermore, all extended endocrine treatment did not bring an overall survival (OS) benefit [13].

The real benefit of extended adjuvant endocrine is unclear. The objectives of the present study were to compare the clinical outcomes of extended $10 \mathrm{y}$ versus $5 \mathrm{y}$ of adjuvant endocrine therapy in patients with early breast cancer.

\section{Methods}

\section{Literature search strategy}

This comprehensive analysis was performed according to the Preferred Reporting Items for Systematic Reviews [14]. PubMed (1966-2017), Embase (1974-2017), the annual meeting abstracts of the European Society of Medical Oncology and American Society of Clinical Oncology were searched. Only prospective studies were permitted to be included in the assessment. The initial search used the following MeSH terms: "Breast cancer OR Breast cancers OR Breast carcinoma" AND "Adjuvant endocrine OR Extended endocrine treatment OR Extended adjuvant endocrine treatment OR Prolonged endocrine treatment OR Prolonged adjuvant endocrine treatment". We also used the following MeSH terms: "Breast cancer OR Breast cancers OR Breast carcinoma" AND "Tamoxifen OR Aromatase Inhibitor OR Exemestane OR letrozole OR anastrozole" AND "Clinical Trial". The PRISMA Checklist is described in Additional file 1: Table S1.

\section{Inclusion and exclusion criteria of the trials}

All the included studies met the following criteria: 1) All trials were prospective, properly randomized controlled and well matched for factors such as age, gender, tumor stage, performance status, clinical stage, treatment regimen, menopausal status, lymph node status, and hormone status. 2) When the same trial was summed up using different time points, only the trial with complete results and the longest follow-up time was included. 3) The primary endpoint was DFS, and the secondary endpoint was OS.
4) After the patients with early breast cancer had completed 5 years of adjuvant endocrine treatment, they were randomly allocated to continue adjuvant endocrine treatment for 5 years or receive placebo for 5 years (or only undergo observation for 5 years).

The exclusion criteria were as follows. 1) All trials concerning neo-adjuvant endocrine treatment were excluded. 2) Ongoing clinical trials without the results of DFS and OS were excluded. 3) Trials involving concomitant interventions, such as adjuvant chemotherapy or radiotherapy, were excluded.

\section{Data extraction}

Three reviewers ( $\mathrm{Li} \mathrm{Li}$ or Bingmei Chang, Xiaoyue Jiang) independently searched the articles. They screened the articles by reading the titles, abstracts or full texts. Any discrepancy was determined by a third reviewer (Shanshan $\mathrm{Wu}$ ). The hazard ratio (HR) or risk ratio (RR) and 95\% confidence interval (CI) of DFS and OS in each trial were extracted. If a trial only provided a Kaplan-Meier curve, the HR and 95\% CI were estimated using the Engauge Digitizer V4.1 screenshot tool and a formula proposed by Parmar $[15,16]$. Related statistical data were extracted by an expert at the Statistics Center (Shanshan Wu). The following information were also extracted and summarized: journal name, publication year, author's name, type of clinical trial, follow-up time, previous endocrine treatment regimens, extended endocrine treatment regimens, primary endpoints, second endpoints, lymph node status, estrogen $(\mathrm{ER})+$ and/ or progesterone (PR) status, and menopausal status. The qualities of the enrolled trials were assessed according to the Cochrane Handbook 4.2.6 for Systematic Reviews of Interventions [17].

\section{Statistical analysis}

Systematic assessment was performed using Stata version 12.0 software (Stata Corporation, College Station, Texas, USA). HR/RR and 95\% CI were collected to estimate the clinical efficacy of DFS and OS. An HR $>1.0$ indicated more recurrence risk or death risk in the extended endocrine treatment group. In each systematic review, Cochrane's $x^{2}$ test was used to evaluate the heterogeneity of the included clinical trials. When the $P$-value of heterogeneity was $<0.05$ or $\mathrm{I}^{2}$ was $>50 \%$, the random-effects model (REM) was used; otherwise, the fixed-effects model (FEM) was used. Begg's and Egger's tests were used to evaluate the publication bias of these trials $[18,19]$.

\section{Results}

\section{Characteristics of the included trials}

Two hundred forty-eight articles were initially identified through searching the PubMed, Embase and abstracts of International Meeting. One hundred seventy-one articles were excluded by checking the titles and abstracts, and 65 
articles were excluded after reading the full text. Finally, 12 trials [4-13, 20] involving 30,848 cases were included in the meta-analysis. The selection flow chart is shown in Fig. 1a, and the design of extended endocrine treatment in all trials is shown in Fig. 1b. The characteristics of the included trials are shown in Table 1. The analysis of Cochrane risk-of-bias showed that the methodological quality of all trials was relatively satisfied and fair.

\section{DFS and OS of extended versus routinely adjuvant endocrine treatment}

As shown in Fig. 2a, twelve trials reported the HR/RR and 95\% CIs for DFS and OS. Among them, nine trials compared the prolonged 10 years of endocrine therapy with 5 years of endocrine therapy. Nine trials were divided into three subgroups as follows: subgroup 1 was
TAM 5y - TAM 5y versus TAM 5y, subgroup 2 was TAM 5y - AI 5y versus TAM 5y - PLA 5y, subgroup 3 was (AI and/or TAM) 5y - LET 5y versus (AI and/or TAM) 5y - PLA 5y. Three trials compared $>8$ y of endocrine therapy with $<8$ y of endocrine therapy.

Significant heterogeneity existed among the studies concerning DFS and DFS1; thus, REM was used to analyze the pooled DFS or pooled DFS1 (DFS: $\mathrm{I}^{2}=72.5 \%, P=0.000$; DFS1: $\left.I^{2}=74.6 \%, P=0.003\right)$. There was no significant heterogeneity among the studies concerning DFS2 and DFS3; thus, FEM was used to analyze the pooled DFS2 or pooled DFS3 (DFS2: $\mathrm{I}^{2}=0.0 \%, P=0.481$; DFS3: $\mathrm{I}^{2}=49.0 \%, P=$ 0.162 ). The overall analysis demonstrated extended endocrine therapy to 10 years of significantly prolonged DFS compared with 5 years of endocrine therapy $(\mathrm{HR}=0.84$, 95\% CI: 0.73-0.97) (Additional file 2: Figure S1A).

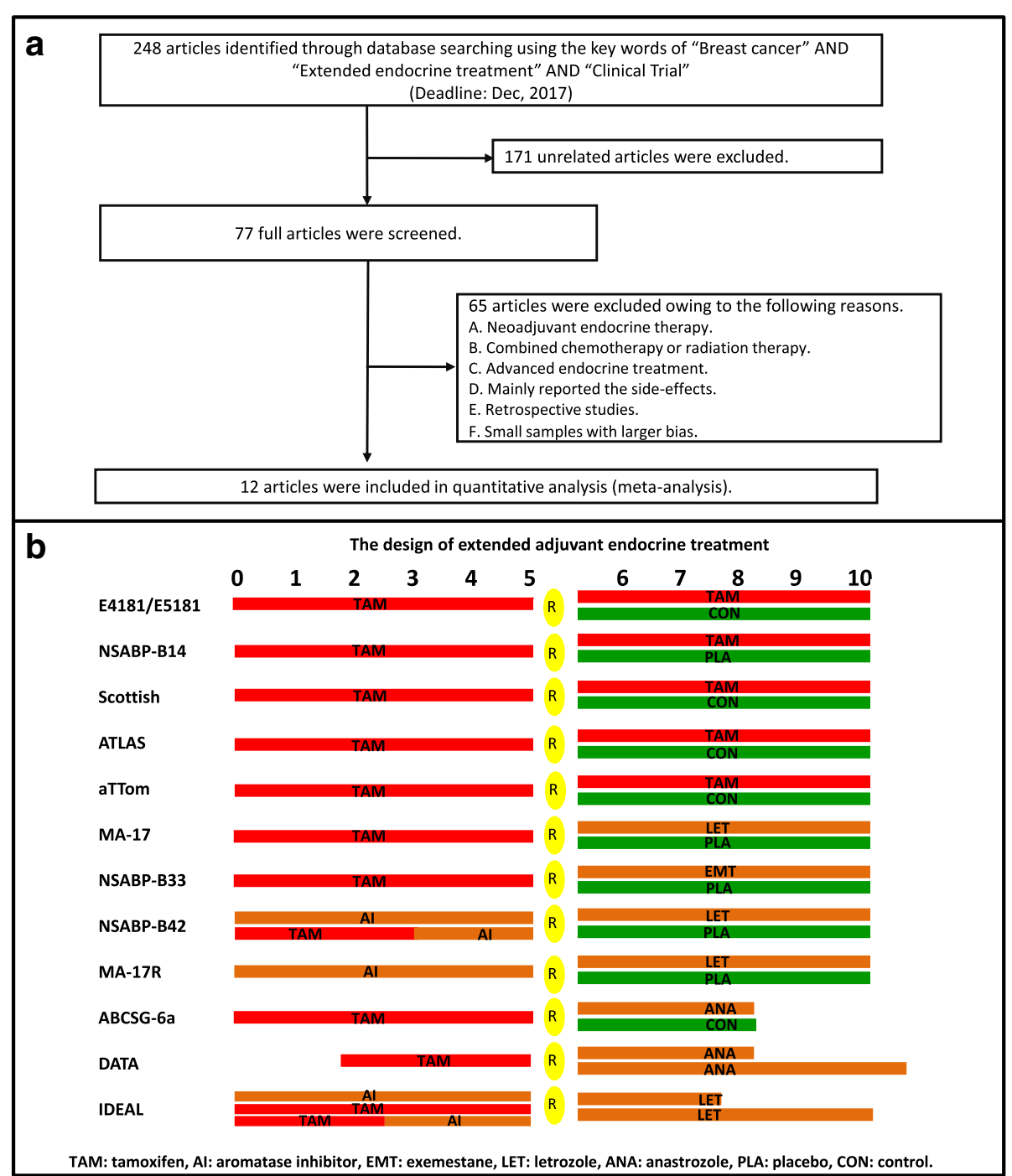

Fig. 1 Inclusion of the studies and design of extended endocrine treatments. a 12 articles were included in quantitative analysis (meta-analysis), b The design of extended adjuvant endocrine treatment 
Table 1 Common characteristics of the studies

\begin{tabular}{|c|c|c|c|c|c|c|c|c|c|c|}
\hline Trial & & Type & $\begin{array}{l}\text { Follow up } \\
\text { time (y) }\end{array}$ & $\begin{array}{l}\text { Previous } \\
\text { treatment }\end{array}$ & $\begin{array}{l}\text { Extended } \\
\text { treatment }\end{array}$ & N & Menopausal State & $\begin{array}{l}\text { Lymph } \\
\text { Node }(+)\end{array}$ & $\begin{array}{l}\text { ER+ and/ } \\
\text { or PR }\end{array}$ & $\begin{array}{l}\text { Primary } \\
\text { endpoint }\end{array}$ \\
\hline \multirow[t]{2}{*}{ E4181/E5181 (1996) } & \multirow[t]{2}{*}{ NR } & \multirow[t]{2}{*}{ Full article } & \multirow[t]{2}{*}{5.6} & TAM 5y & \multirow[t]{2}{*}{ TAM 5y } & 100 & \multirow{2}{*}{$\begin{array}{l}\text { Premenopausal } \\
\text { /Postmenopausal }\end{array}$} & $100 / 100$ & \multirow[t]{2}{*}{$73 \%$ ER+ } & \multirow[t]{2}{*}{ DFS } \\
\hline & & & & TAM $5 y$ & & 93 & & 93/93 & & \\
\hline \multirow[t]{2}{*}{ NSABP-B14 (2001) } & \multirow[t]{2}{*}{ III } & \multirow[t]{2}{*}{ Full article } & \multirow[t]{2}{*}{6.8} & TAM 5y & TAM 5y & 593 & \multirow{2}{*}{$\begin{array}{l}\text { Premenopausal } \\
\text { /perimenopausal } \\
\text { /Postmenopausal }\end{array}$} & Negative & ER+ & \multirow[t]{2}{*}{ DFS } \\
\hline & & & & TAM 5y & Placebo $5 y$ & 579 & & Negative & ER+ & \\
\hline \multirow[t]{2}{*}{ Scottish trial (2001) } & \multirow[t]{2}{*}{ NR } & \multirow[t]{2}{*}{ Full article } & \multirow[t]{2}{*}{15.0} & TAM 5y & \multirow[t]{2}{*}{ TAM 5y } & 173 & \multirow{2}{*}{$\begin{array}{l}\text { Premenopausal } \\
\text { /Postmenopausal }\end{array}$} & 43/90a & $66 / 173 b$ & \multirow[t]{2}{*}{ DFS } \\
\hline & & & & TAM 5y & & 169 & & $35 / 89$ & $66 / 169$ & \\
\hline \multirow[t]{2}{*}{ ATLAS (2013) } & \multirow[t]{2}{*}{ III } & \multirow[t]{2}{*}{ Full article } & \multirow[t]{2}{*}{15.0} & TAM 5y & \multirow[t]{2}{*}{ TAM 5y } & 3428 & \multirow{2}{*}{$\begin{array}{l}\text { Premenopausal } \\
\text { /perimenopausal } \\
\text { /Postmenopausal }\end{array}$} & $1474 / 3428$ & ER+ & \multirow[t]{2}{*}{ DFS } \\
\hline & & & & TAM 5y & & 3418 & & $1427 / 3418$ & ER+ & \\
\hline \multirow[t]{2}{*}{ aTTom (2013) } & \multirow[t]{2}{*}{ III } & \multirow[t]{2}{*}{ Abstract } & 8.6 & TAM 5y & TAM 5y & 3468 & Premenopausal & $N R$ & ER+/untested & DFS \\
\hline & & & & TAM 5y & & 3485 & /Postmenopausal & & & \\
\hline MA.17 (2005) & III & Full article & 2.5 & TAM 5y & LET $5 y$ & 2593 & postmenopausal & $1171 / 2583$ & $2516 / 2583$ & DFS \\
\hline & & & & TAM $5 y$ & Placebo 5y & 2594 & & $1189 / 2587$ & $2519 / 2587$ & \\
\hline NSABP-B33 (2008) & III & Full article & 2.5 & TAM 5y & EMT 5y & 799 & postmenopausal & $384 / 799$ & 775/799 & DFS \\
\hline & & & & TAM 5y & Placebo 5y & 799 & & $384 / 779$ & 759/799 & \\
\hline NSABP-B42 (2016) & III & Abstract & 6.9 & Al $5 y$ & LET $5 y$ & 1959 & postmenopausal & NR & 1959/1959 & DFS \\
\hline & & & & $\begin{array}{l}\text { TAM } \\
3 y-A I \text { 2y }\end{array}$ & Placebo 5y & 1964 & & & $1964 / 1964$ & \\
\hline MA-17R (2016) & III & Full article & 6.3 & Al $4.5-6$ y & LET $5 y$ & 959 & postmenopausal & $492 / 959$ & $945 / 959$ & DFS \\
\hline & & & & $\begin{array}{l}\text { TAM-Al } \\
4.5-6 \text { y }\end{array}$ & Placebo $5 y$ & 959 & & $494 / 959$ & 950/959 & \\
\hline ABCSG-6a (2007) & III & Full article & 5.2 & TAM5y & ANA 3y & 387 & postmenopausal & $132 / 387$ & $371 / 387$ & DFS \\
\hline & & & & TAM 5y & & 469 & & $146 / 469$ & $454 / 469$ & \\
\hline DATA (S1-03) (2016) & III & Abstract & 4.1 & TAM 2-3y & ANA 6y & 931 & postmenopausal & $561 / 827$ & $827 / 827$ & DFS \\
\hline & & & & TAM 2-3y & ANA 3y & 929 & & $551 / 827$ & $833 / 833$ & \\
\hline IDEAL(S1-04) (2017) & III & Abstract & 6.4 & $\begin{array}{l}(\mathrm{Al} / \mathrm{TAM} / \mathrm{TAM}-\mathrm{Al}) \\
5 \mathrm{y}\end{array}$ & LET $5 y$ & $N R$ & postmenopausal & partial positive & $\mathrm{HR}+$ & DFS \\
\hline & & & & $\begin{array}{l}(\mathrm{Al} / \mathrm{TAM} / \mathrm{TAM}-\mathrm{Al}) \\
5 \mathrm{y}\end{array}$ & LET 2.5y & NR & & & & \\
\hline
\end{tabular}

TAM tamoxifen, $A$ l aromatase inhibitor, EMT exemestane, LET letrozole, ANA anastrozole, ER estrogen, $H R$ hormone receptor, DFS disease free survival

Subgroup 2 and subgroup 3 analysis showed that TAM 5y AI 5y and (AI and/or TAM) 5y - LET 5y treatment significantly prolonged DFS compared with TAM 5y and (AI and/ or TAM) 5y treatment, respectively $(\mathrm{HR}=0.61,95 \% \mathrm{CI}$ : 0.50-0.76; $\mathrm{HR}=0.81,95 \% \mathrm{CI}$ : 0.71-0.93) (Additional file 2: Figure S1C, 1D). However, no significant difference was found in the DFS between the TAM 5y - TAM 5y group and TAM 5y group ( $\mathrm{HR}=0.97,95 \% \mathrm{CI}$ : 0.81-1.17) (Additional file 2: Figure S1B). The DFS rates of 10 years of endocrine therapy in the NSABP-B14 and Scottish trials were significantly lower than those of 5 years of endocrine treatment, whereas the DFS rates of 10 years of endocrine therapy in seven other trials were increased compared with those of 5 years of endocrine treatment (Fig. 2b).

There was significant heterogeneity among the studies concerning OS and OS1; thus, REM was applied to analyze the pooled OS or pooled OS1 (OS: $\mathrm{I}^{2}=$
55.4\%, $P=0.028 ;$ OS1: $\left.\mathrm{I}^{2}=64.2 \%, P=0.025\right)$. No significant heterogeneity was found among the studies concerning OS2 and OS3; thus, FEM was used (OS2: $\mathrm{I}^{2}=0.0 \%, P=0.368 ;$ OS $\left.3: \mathrm{I}^{2}=0.0 \%, P=0.323\right)$. $(\mathrm{HR}=$ 1.01, 95\% CI: 0.90-1.14; HR =1.02, 95\% CI: 0.87-1.19; $\mathrm{HR}=0.88, \quad 95 \%$ CI: $0.64-1.23 ; \quad \mathrm{HR}=1.09, \quad 95 \% \mathrm{CI}$ : 0.93-1.28, respectively) (Fig. 3).

As shown in Additional file 3: Figure S2, three trials reported the HR/RR and 95\% CIs for DFS and OS, which compared the efficacy of $>8$ y of endocrine therapy with that of $<8$ y of endocrine therapy. FEM was used to analyze the pooled DFS and pooled OS. Greater than $8 \mathrm{y}$ of endocrine treatment significantly improved DFS compared with $<8$ y of endocrine treatment $(\mathrm{HR}=$ 0.78, 95\% CI: 0.66-0.94). However, no significant improvement was found in OS between the two groups $(\mathrm{HR}=0.95$, 95\% CI: 0.76-1.19). 


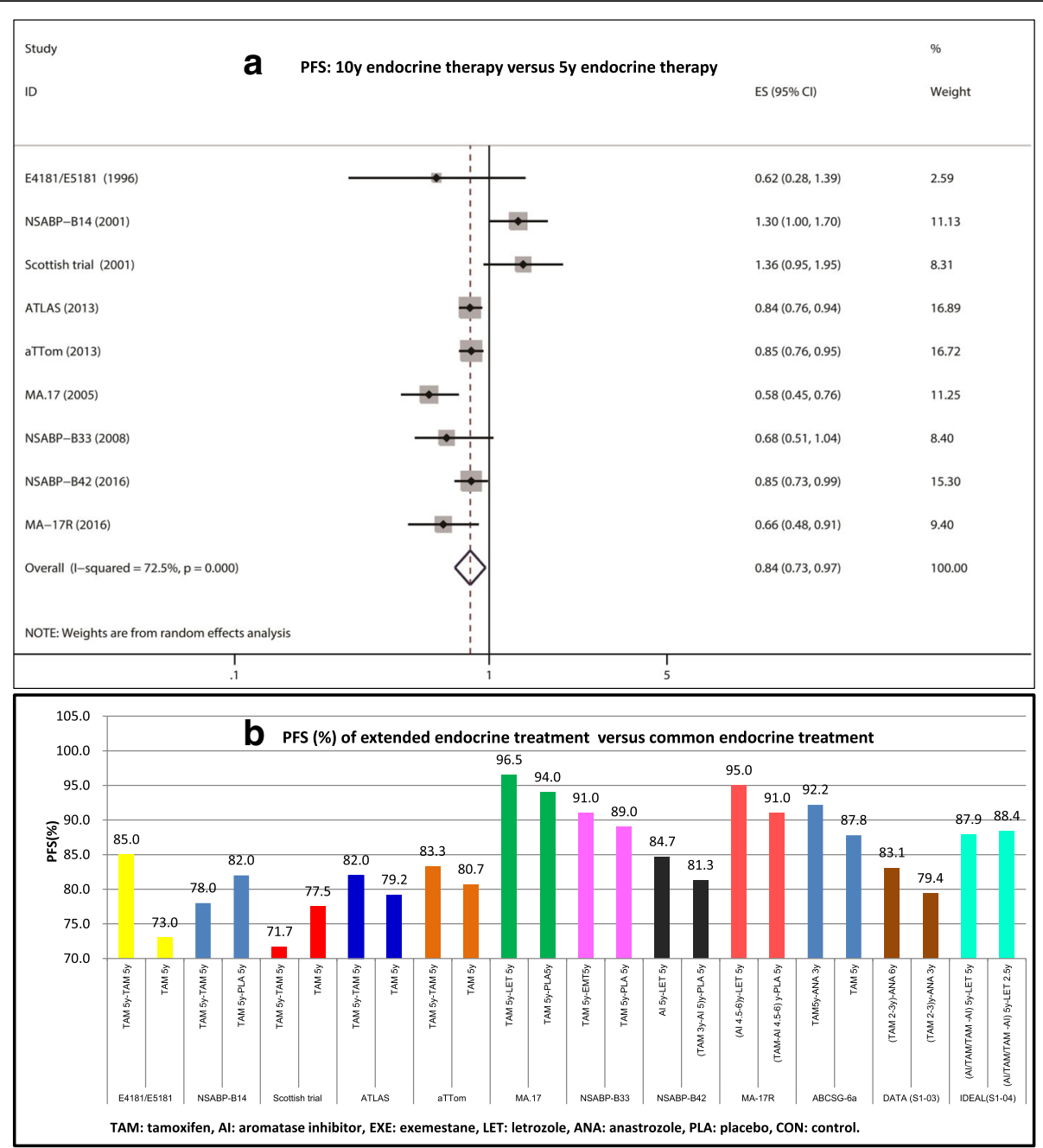

Fig. 2 DFS analysis of 10-y endocrine therapy versus 5-y endocrine therapy. a PFS: 10y endocrine therapy versus 5y endocrine therapy, b PFS (\%) of extended endocrine treatment versus common endocrine treatment

DFS analysis in the lymph node-positive subgroup

As shown in Fig. 4a and b, three trials reported the data of $\mathrm{HR} / \mathrm{RR}$ and $95 \%$ CIs for DFS in the lymph node-positive subgroup. No significant heterogeneity was found among the studies, and FEM was used $\left(\mathrm{I}^{2}=0.00 \%, P=0.806\right)$. The analysis showed that extended endocrine therapy to 10 years significantly improved DFS compared with 5 years of endocrine therapy in the lymph node-positive subgroup ( $\mathrm{HR}=0.58$, 95\% CI: 0.45-0.75). In MA.17, positive results of extended endocrine treatment were seen in both the lymph node-positive and -negative groups.

\section{DFS analysis in the postmenopausal subgroup}

As shown in Fig. 5a and b, seven trials reported the data of $\mathrm{HR} / \mathrm{RR}$ and $95 \%$ CIs for DFS in the postmenopausal subgroup. Postmenopausal subgroup analysis showed that extended endocrine therapy to 10 years significantly improved DFS compared with 5 y of endocrine therapy
$(\mathrm{HR}=0.70$, 95\% CI: 0.58-0.85). A similar result was observed between $>8$ y of endocrine therapy and $<8$ y of endocrine therapy ( $\mathrm{HR}=0.76,95 \% \mathrm{CI}: 0.62-0.93)$. In the ATLAS, MA.17, NSABP-B33, NSABP-B42, MA-17R, ABCSG-6a and DATA trials, the recurrences rates in the extended group and non-extended group were 17.7\% versus $20.5 \%, 3.6 \%$ versus $6.0 \%$, $4.6 \%$ versus $6.5 \%, 14.9 \%$ versus $17.3 \%, 7.0 \%$ versus $10.2 \%, 7.8 \%$ versus $12.2 \%$, and $14.0 \%$ versus $17.4 \%$, respectively.

DFS analysis in the ER+ subgroup and/or PR+ subgroup As shown in Fig. 6a and b, six trials reported the data of HR/RR and 95\% CIs for DFS in the ER+ subgroup and/or $\mathrm{PR}+$ subgroup. There was significant heterogeneity among the studies; thus, REM analysis was conducted $\left(\mathrm{I}^{2}=76.7 \%\right.$, $P=0.001)$. ER+ and/or PR+ subgroup analysis showed that extended endocrine therapy to 10 years significantly improved DFS compared with 5 years of endocrine therapy 


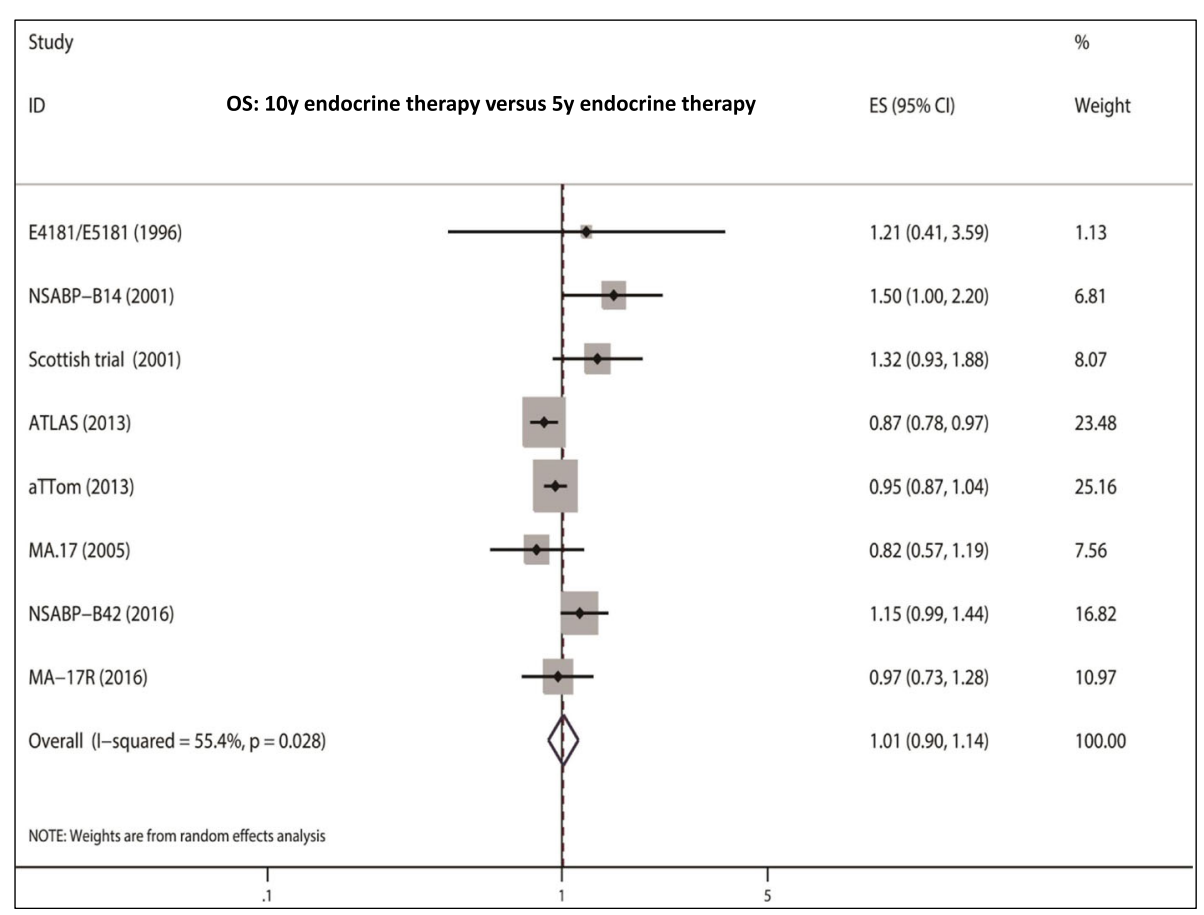

Fig. 3 OS analysis of 10-y endocrine therapy versus 5-y endocrine therapy

$(\mathrm{HR}=0.80$, 95\% CI: 0.67-0.96). In the NSABP-B14 trial, the recurrence rate in the TAM 5y - TAM 5y group was higher than that of the TAM 5y group (23.5\% versus $18.6 \%$, respectively). However, in the ATLAS, MA.17, NSABP-B33, NSABP-B42, and MA-17R trials, the recurrence rates in the extended treatment groups were lower than those in the 5 years of endocrine treatment group (17.8\% versus $20.8 \%, 3.7 \%$ versus $6.1 \%, 4.8 \%$ versus $6.9 \%$, $14.9 \%$ versus $17.3 \%$, and $7.1 \%$ versus $10.3 \%$, respectively).

\section{Discussion}

Five years of adjuvant endocrine therapy has been verified to significantly reduce the recurrence risk and cancer mortality in ER+, early-stage breast cancer [20]. Whether extended endocrine therapies could further increase the clinical benefit has always been a controversial topic. Some trials have shown that extended endocrine therapies could further lower the recurrence risk. However, IDEAL trials demonstrated that (AI/ TAM/TAM-AI) 5y - LET 5y did not bring significant prolongation for DFS and OS compared with (AI/TAM/ TAM-AI) 5y - LET 2.5y [8]. Additionally, in the Scottish and NSABP-B14 trials, extended TAM to 10 years was confirmed to decrease DFS compared with 5 years of treatment $[12,13]$. The optimal time of extended endocrine treatment is a controversial hot topic for oncologists. Our study comprehensively analyzed the related clinical trials, and the results showed that extended 10 years of adjuvant endocrine treatment was more efficacious than "standard" 5 years of endocrine treatment in preventing recurrence. Unfortunately, extended endocrine therapy to 10 years are not verified to improve OS, and this might mainly influenced by the efficacy of multiline therapy after relapse. It should not be overlooked that the overall follow-up time is not long, so a very long term follow-up is needed in these populations to prove OS differences. Considering the difference in the research populations and backgrounds in different trials, clinical application of extended endocrine treatment should be carefully weighed.

The debates concerning extended TAM treatment is obvious. The time of extended endocrine therapy is an important factor affecting the conclusion. The ATLAS and aTTom trials reported that extended adjuvant TAM for more than 10 years provides further protection against recurrence; however, 5-9 years of application did not exert a positive effect $[9,10]$. Saphner reported that the mean recurrence rate of 5-10 years was $4.3 \%$ per year; 5-9 years of extended endocrine treatment might not be the most advantageous with a lower recurrence risk [21]. With the increase in the recurrence risk after 10 years, extended adjuvant TAM for more than 10 years probably shows significant clinical efficacy. In the process, identifying patients with high-risk recurrence is the key factor to guide treatment.

The difference in drugs in extended endocrine treatment might affect the conclusion. Coombes $\mathrm{RC}$ reported that the DFS and OS in the (TAM-EXE) 5y group were 


\begin{tabular}{|c|c|c|c|c|c|c|c|c|c|}
\hline \multicolumn{7}{|c|}{$\begin{array}{l}\text { A PFS: 10y endocrine therapy versus } 5 y \text { endocrine therapy } \\
\text { in lymph node positive group }\end{array}$} & \multicolumn{3}{|c|}{ ES $(95 \% \mathrm{Cl})$} \\
\hline \multicolumn{7}{|l|}{ ECOG E4181 } & \multicolumn{2}{|c|}{$0.62(0.28,1.39)$} & 10.10 \\
\hline \multicolumn{2}{|l|}{ MA.17 } & & & & & & \multicolumn{2}{|c|}{$0.61(0.45,0.84)$} & 66.53 \\
\hline \multicolumn{4}{|l|}{ NSABP-B33 } & & & & \multicolumn{2}{|c|}{$0.50(0.30,0.86)$} & 23.37 \\
\hline \multicolumn{2}{|c|}{ Overall (1-squared $=0.0 \%, p=0.806$ ) } & & & & & & \multicolumn{2}{|c|}{$0.58(0.45,0.75)$} & 100.00 \\
\hline \multicolumn{4}{|c|}{.1} & \multicolumn{3}{|c|}{5} & & & \\
\hline \multicolumn{10}{|c|}{ b PFS analysis in lymph node positive group and negative group } \\
\hline \multirow{2}{*}{\multicolumn{2}{|c|}{ Group }} & & & \multicolumn{3}{|c|}{ lymph node positive } & \multicolumn{3}{|c|}{ lymph node negative } \\
\hline & & $\mathrm{N}$ & $\mathrm{n}$ & HR & $95 \% \mathrm{CI}$ & $\mathrm{P}$ & $\mathrm{HR}$ & $95 \% \mathrm{CI}$ & $P$ \\
\hline \multicolumn{10}{|l|}{ Subgroup 1} \\
\hline ECOG E4181 & $\begin{array}{l}\text { TAM 5y-TAM 5y } \\
\text { TAM } 5 y\end{array}$ & & $\begin{array}{l}17 \\
29\end{array}$ & 0.62 & $0.28-1.39$ & & & & \\
\hline \multirow[t]{2}{*}{ ATLAS } & TAM 5y-TAM 5y & 1596 & 365 & 0.83 & & 0.070 & 0.85 & & 0.080 \\
\hline & TAM $5 y$ & 1573 & 416 & & & & & & \\
\hline \multirow[t]{2}{*}{ NSABP-B14 } & TAM 5y-TAM 5y & 583 & 137 & & & & 1.30 & $1.00-1.70$ & 0.030 \\
\hline & TAM 5y-PLA 5y & 569 & 106 & & & & & & \\
\hline \multicolumn{10}{|l|}{ Subgroup 2} \\
\hline MA.17 & $\begin{array}{l}\text { TAM 5y-LET 5y } \\
\text { TAM 5y-PLA 5y }\end{array}$ & $\begin{array}{l}1171 \\
1189\end{array}$ & $\begin{array}{l}\mathrm{NR} \\
\mathrm{NR}\end{array}$ & 0.61 & $0.45-0.84$ & & 0.45 & $0.27-0.73$ & \\
\hline NSABP-B33 & $\begin{array}{l}\text { TAM 5y-EMT 5y } \\
\text { TAM 5y-PLA 5y }\end{array}$ & $\begin{array}{l}384 \\
384\end{array}$ & $\begin{array}{l}\mathrm{NR} \\
\mathrm{NR}\end{array}$ & 0.50 & $0.30-0.86$ & 0.010 & 1.13 & & 0.740 \\
\hline ABCSG-6a & $\begin{array}{l}\text { TAM5y-ANA3y } \\
\text { TAM 5y }\end{array}$ & $\begin{array}{l}\mathrm{NR} \\
\mathrm{NR}\end{array}$ & $\begin{array}{l}\mathrm{NR} \\
\mathrm{NR}\end{array}$ & 0.61 & $0.34-1.10$ & 0.097 & 0.61 & $0.31-1.18$ & 0.140 \\
\hline DATA (S1-03) & $\begin{array}{l}\text { (TAM 2-3y)-ANA 6y } \\
\text { (TAM 2-3y)-ANA 3y }\end{array}$ & $\begin{array}{l}\mathrm{NR} \\
\mathrm{NR}\end{array}$ & $\begin{array}{l}\mathrm{NR} \\
\mathrm{NR}\end{array}$ & 0.71 & $0.53-0.96$ & 0.023 & & & \\
\hline
\end{tabular}

Fig. 4 DFS analysis in the lymph node-positive group. a PFS: 10y endocrine therapy versus 5y endocrine therapy in lymph node positive group, b PFS analysis in lymph node positive group and negative group

significant improved compared with those in the TAM 5y group [22]. The 10-year breast cancer mortality was $12.1 \%$ after 5 years of AI treatment, a value that was lower than $14.2 \%$ after 5 years of TAM treatment [23], and 5 years of AI showed an advantage over 5 years of TAM in decreasing the 10-year mortality risk. The extended 3 years of ANA after 5 years of TAM showed a significant DFS reduction of 36\% (ABCSG-6a) [24], and the extended 5 years of LET after 5 years of TAM showed a significant DFS reduction of $42 \%$ [3]. Our subgroup analysis showed that TAM 5y - AI 5y and (AI and/or TAM) 5y - LET 5y significantly prolonged DFS compared with TAM 5y. These data indicated that extended AI treatment is a valid therapeutic option for early breast cancer. However, the conclusions of continuous 10 years of TAM were not consistent. The
NSABP-B14, Scottish and E4181/E5181 trials reported that an additional benefit was not observed in the TAM $5 y$ - TAM 5y arms [11-13]. However, the ATLAS and aTTom trials reported that a prolonged 10 years of TAM significantly reduced the recurrence risk $[9,10]$. Our subgroup analysis verified that continuous 10 years of TAM did not improve DFS compared with 5 years of TAM.

The following factors are closely related to the efficacy of extended endocrine therapy: (1) Hormone receptor status. In hormone receptor-positive patients, 5 years of TAM treatment decreased the 5-y and 10-y breast cancer recurrence rates from 26.1 and $37.7 \%$ to $15.4 \%$ and $24.8 \%$, respectively; however, the treatment could not decrease the recurrence rates in hormone receptor-negative patients [25]. In $6 \mathrm{ER}+$ and/or PR+ trials, five trials (ATLAS, 


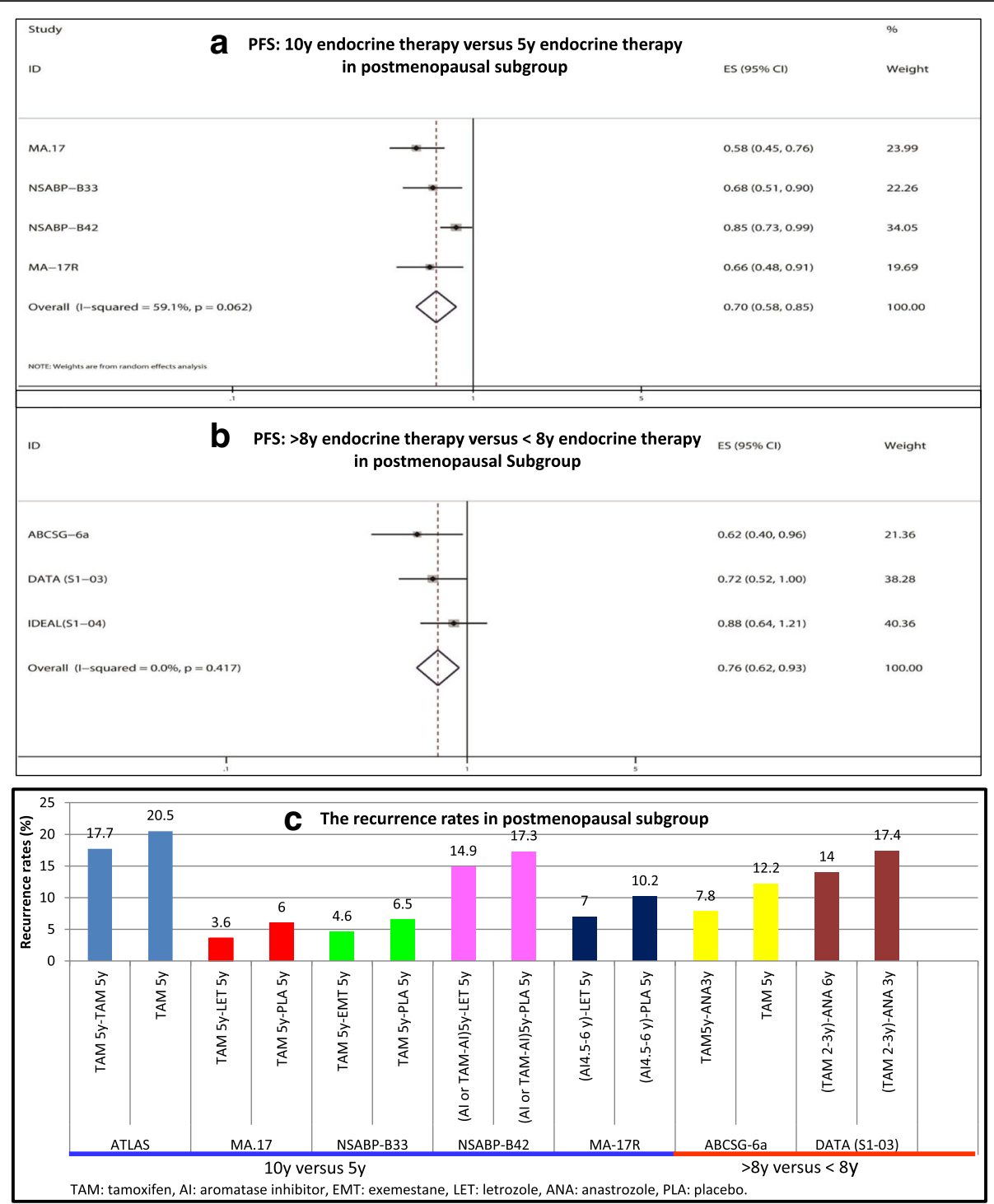

Fig. 5 DFS analysis in the postmenopausal subgroup. a PFS: 10y endocrine therapy versus $5 y$ endocrine therapy in postmenopausal subgroup, b PFS: $>8 y$ endocrine therapy versus $<8$ y endocrine therapy in postmenopausal subgroup

MA.17, NSABP-B33, NSABP-B42, MA-17R) showed the superiority of 10 years of endocrine treatment $[4-7,9]$, whereas only the NSABP-B14 trial reported an opposite conclusion [13]. Our comprehensive analysis showed that 10 years of endocrine treatment further reduced the breast cancer recurrence rate and significantly improved DFS compared with 5 years of endocrine treatment $(\mathrm{HR}=0.80,95 \% \mathrm{CI}: 0.67-0.96)$ in $\mathrm{ER}+$ and/or PR + patients. (2) Menstrual status. The ATLAS stratified study showed that extended TAM treatment seemed to have a beneficial effect in preventing recurrence in postmenopausal women ( $R R=0.85, P=0.05)$ but has no effect in premenopausal women $(\mathrm{RR}=0.81, P=0.15)$ [9]. In postmenopausal women, 5y TAM - 5y AI led to significant improvement in DFS; in the MA.17 trial, it led to OS improvement in the high-risk node-positive subset [4]. Our meta-analysis showed that extended endocrine therapy to 10 years significantly improved DFS in postmenopausal women (HR $=0.70$, 95\% CI: 0.58 0.85). (3) Lymph node status. The late recurrence risk in breast cancer patients with more than three positive nodes was 2.18-fold that in patients without lymph node metastasis after the completion of 5 years of adjuvant endocrine therapy [26]. In theory, the extended endocrine therapy should exert a clinical benefit in these patients with a lymph node-positive status. Unfortunately, the ATLAS trial showed that 10-year TAM treatment could not improve DFS compared 5 years of TAM in lymph node-positive or -negative patients [9]. 5y TAM-5y AI treatment only improved DFS compared with 5y TAM 


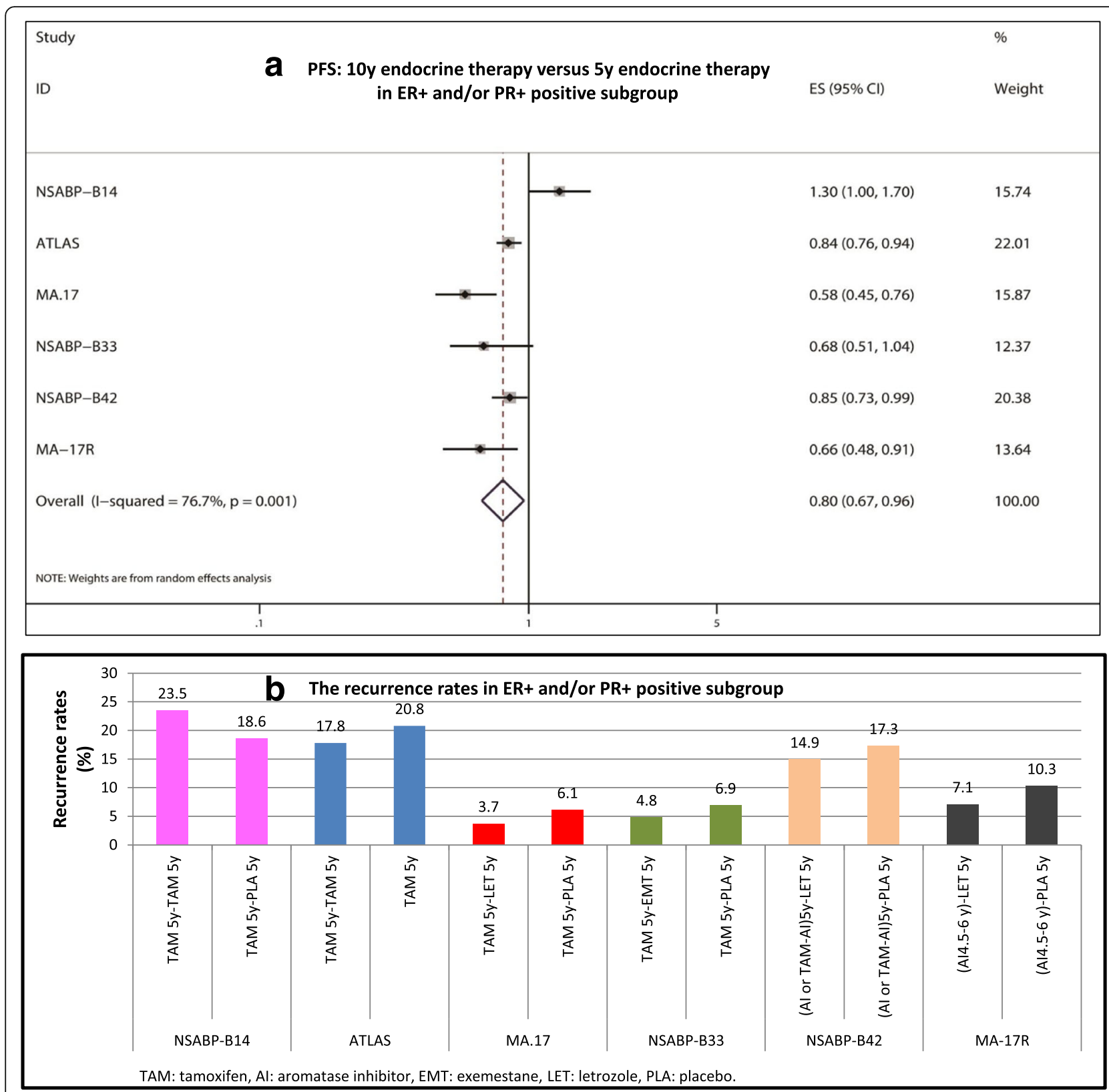

Fig. 6 DFS analysis in ER+ and/or PR+ positive subgroup. a PFS: 10y endocrine therapy versus 5y endocrine therapy in ER+ and/or PR+ positive subgroup, $\mathbf{b}$ The recurrence rates in ER+ and/or PR+ positive subgroup

treatment in lymph node-positive patients, and the corresponding results in lymph node-negative patients were uniform $[4,7]$. The mode of TAM 5y -AI $5 y$ is worth recommending in lymph node-positive patients.

The clinical efficacy and side effects are two determining factors for extended endocrine treatment. Serious adverse effects will interrupt the persistence of endocrine treatment $[27,28]$. The Ideal study reported that $15.7 \%$ patients discontinued extended 2.5 years of LET treatment because of toxicities [8]. However, the MA17R trial showed that it was safe and beneficial for women with HR-positive breast cancer to receive AI for another 5 years after initial treatment; the incidence of toxic effects was lower except that bone-related events occurred more frequently than those in the placebo group (14.0\% versus $9.0 \%$, respectively) [6]. Moreover, the discontinuation rate of extended AI for 5 years was $6.0 \%$ due to bone fracture, a value similar to that for the placebo. Extended AI to 10 years may be recommended when improved DFS is accompanied by a lower incidence rate of toxic effects. The reported ratios of endometrial cancer in the TAM 5y - TAM 5y group were 2.1, 
1.7 and 2.2 folds compared with those in the TAM 5y group in the NSABP-B-14, ATLAS and aTTOM trials, respectively $[9,10,13]$. The TMA 5y - TAM 5y strategy may not be recommended with no improvement in DFS and higher incidence rates of endometrial cancer. Sequential treatment with different types of endocrine drugs is also used to maintain the efficacy to a maximum and decrease adverse effects to a minimum.

\section{Conclusion}

Based on standard 5-year endocrine treatment, extended endocrine treatment to 10 years could further bring a DFS benefit for patients with early breast cancer, especially in the AI and/or TAM 5y - AI 5y mode, ER+ subgroup and/or $\mathrm{PR}+$ subgroup, postmenopausal subgroup and lymph node-positive subgroup. Of course, the recognition of patients with the highest recurrence risk will help to obtain more clinical benefit from extended endocrine treatment, and gene analysis or molecular markers will be used to guide individualized endocrine therapy.

\section{Additional files}

Additional file 1: Table S1. PRISMA Checklist. (DOC 67 kb)

Additional file 2: Figure S1. DFS subanalysis of 10-y endocrine therapy versus 5-y endocrine therapy. (PDF $191 \mathrm{~kb}$ )

Additional file 3: Figure S2. DFS and OS analysis of $>8$ years of endocrine therapy versus $<8$ years of endocrine therapy. (PDF $184 \mathrm{~kb}$ )

\section{Abbreviations}

Al: Aromatase inhibitor; DFS: Disease-free survival; EMT: Exemestane; FEM: Fixed-effects model; LET: Letrozole; NSABP: National Surgical Adjuvant Breast and Bowel Project; OS: Overall survival; REM: Random-effects model; TAM: Tamoxifen

\section{Acknowledgements}

We thank for the help of Statistical Center of Beijing Friendship Hospital.

\section{Funding}

This study was funded by the National Natural Science Foundation of China (Grant NO. 81301912), Beijing Municipal Health System High-level Health Person Foundation Project (Grant NO. 2014-3-005), Beijing Municipal Science and Technology Commission Foundation (Capital Features, Z161100000516083, to Qin Li) and Natural Science Foundation of Capital Medical University (to Qin Li). Funding bodies were not involved in the design of the study, collection, analysis, and interpretation of data or in writing the manuscript.

\section{Availability of data and materials}

All data generated or analyzed during this study are included in this published article (and its supplementary information files).

\section{Authors' contributions}

QL designed the research and was responsible for the integrity of the data and accuracy of the data analysis. $L L, B C$ and $X J$ contributed to the literature search, studies selection and figures. BC, XF and YL developed methodology. $\mathrm{LL}$ drafted the manuscript. TL and SW participated in studies selection and data extraction and statistical analysis. JZ and SK interpreted the results and polished the manuscript. QL reviewed and edited the manuscript extensively. All authors contributed to the review and approved the paper. All authors agreed to be accountable for the content of this paper.
Ethics approval and consent to participate

Not applicable

\section{Consent for publication}

Not applicable

\section{Competing interests}

The authors declare that they have no competing interests.

\section{Publisher's Note}

Springer Nature remains neutral with regard to jurisdictional claims in published maps and institutional affiliations.

\section{Author details}

${ }^{1}$ Department of Oncology, Beijing Friendship Hospital, Capital Medical University, Beijing 100050, China. ${ }^{2}$ Department of Biochemistry and Molecular Biology, Basic Medical College, Shanxi Medical University, Taiyuan 030001, China. ${ }^{3}$ Gastroenterology Department, JinCheng People's Hospital, Shanxi 048000, China. ${ }^{4}$ Biochemistry and Molecular Biology, Basic Medicine College, Shanxi Medical University, Taiyuan 050001, China. ${ }^{5}$ Statistical Center, Beijing Friendship Hospital, Capital Medical University, Beijing 100050, China.

${ }^{6}$ Department of Hematopathology, University of Texas MD Anderson Cancer Center, Houston 77030, USA. ${ }^{7}$ Molecular and Cellular Oncology, MD Anderson Cancer Center, 1515 Holcombe Blvd, Houston 77030, USA

Received: 14 May 2018 Accepted: 1 October 2018

Published online: 12 October 2018

References

1. Ferreira AR, Palha A, Correia L, Filipe $P$, Rodrigues V, Miranda A, André $R$, Fernandes J, Gouveia J, Passos-Coelho JL, Moreira A, Brito M, Ribeiro J, Metzger-Filho O, Lin NU, Costa L, Vaz-Luis I. Treatment adoption and relative effectiveness of aromatase inhibitors compared to tamoxifen in early breast cancer: a multi-institutional observational study. Breast. 2018;37:107-13.

2. Early Breast Cancer Trialists' Collaborative Group. Tamoxifen for early breast cancer: an overview of the randomised trials. Lancet. 1998;351:1451-67.

3. Early Breast Cancer Trialists' Collaborative Group (EBCTCG). Effects of chemotherapy and hormonal therapy for early breast cancer on recurrence and 15-year survival: an overview of the randomised trials. Lancet. 2005;365: $1687-717$

4. Goss PE, Ingle JN, Martino S, Robert NJ, Muss HB, Piccart MJ, Castiglione M, Tu D, Shepherd LE, Pritchard Kl, Livingston RB, Davidson NE, Norton L, Perez EA Abrams JS, Cameron DA, Palmer MJ, Pater JL. Efficacy of letrozole extended adjuvant therapy according to estrogen receptor and progesterone receptor status of the primary tumor: National Cancer Institute of Canada Clinical Trials Group MA.17. J Clin Oncol. 2007;25:2006-11.

5. Mamounas EP, Lembersky B, Jeong JH, Cronin W, Harkins B, Geyer C, Wickerham DL, Paik S, Costantino J, Wolmark N. NSABP B-42: a clinical trial to determine the efficacy of five years of letrozole compared with placebo in patients completing five years of hormonal therapy consisting of an aromatase inhibitor (Al) or tamoxifen followed by an Al in prolonging disease-free survival in postmenopausal women with hormone receptorpositive breast cancer. Clin Breast Cancer. 2006;7:416-21.

6. Goss PE, Ingle JN, Pritchard Kl, Robert NJ, Muss H, Gralow J, Gelmon K, Whelan T, Strasser-Weippl K, Rubin S, Sturtz K, Wolff AC, Winer E, Hudis C, Stopeck A, Beck JT, Kaur JS, Whelan K, Tu D, Parulekar WR. Extending aromatase-inhibitor adjuvant therapy to 10 years. N Engl J Med. 2016;375:209-19.

7. Mamounas EP, Jeong JH, Wickerham DL, Smith RE, Ganz PA, Land SR, Eisen A, Fehrenbacher L, Farrar WB, Atkins JN, Pajon ER, Vogel VG, Kroener JF, Hutchins LF, Robidoux A, Hoehn JL, Ingle JN, Geyer CE, Costantino JP, Wolmark N. Benefit from exemestane as extended adjuvant therapy after 5 years of adjuvant tamoxifen: intention-to-treat analysis of the National Surgical Adjuvant Breast and Bowel Project B-33 trial. J Clin Oncol. 2008;26:1965-71.

8. Blok EJ, Kroep JR, Meershoek-Klein KE, Duijm-de CM, Putter H, van den Bosch J, Maartense E, van Leeuwen-Stok AE, Liefers GJ, Nortier JWR, Rutgers EJT, van de Velde CJH. Optimal duration of extended adjuvant endocrine therapy for early breast cancer; results of the IDEAL trial (BOOG 2006-05). J Natl Cancer Inst. 2018;110:djx134.

9. Davies C, Pan H, Godwin J, Gray R, Arriagada R, Raina V, Abraham M, Medeiros AVH, Badran A, Bonfill X, Bradbury J, Clarke M, Collins R, Davis SR, Delmestri A, Forbes JF, Haddad P, Hou MF, Inbar M, Khaled H, Kielanowska 
J, Kwan WH, Mathew BS, Mittra I, Müller B, Nicolucci A, Peralta O, Pernas F, Petruzelka L, Pienkowski T, Radhika R, Rajan B, Rubach MT, Tort S, Urrútia G, Valentini M, Wang Y, Peto R. Long-term effects of continuing adjuvant tamoxifen to 10 years versus stopping at 5 years after diagnosis of oestrogen receptor-positive breast cancer: ATLAS, a randomised trial. Lancet. 2013;381:805-16.

10. Azim HA, Saadeldeen A. Commentary on "aTTom": long-term effects of continuing adjuvant tamoxifen to 10 years. Chin Clin Oncol. 2014;3:7.

11. Tormey DC, Gray R, Falkson HC. Postchemotherapy adjuvant tamoxifen therapy beyond five years in patients with lymph node-positive breast cancer. Eastern Cooperative Oncology Group. J Natl Cancer Inst. 1996;88: 1828-33.

12. Stewart HJ, Prescott RJ, Forrest AP. Scottish adjuvant tamoxifen trial: a randomized study updated to 15 years. J Natl Cancer Inst. 2001;93:456-62.

13. Fisher B, Dignam J, Bryant J, Wolmark N. Five versus more than five years of tamoxifen for lymph node-negative breast cancer: updated findings from the National Surgical Adjuvant Breast and Bowel Project B-14 randomized trial. J Natl Cancer Inst. 2001;93:684-90.

14. Moher D, Liberati A, Tetzlaff J, Altman DG. Preferred reporting items for systematic reviews and meta-analyses: the PRISMA statement. PLoS Med. 2009;6:e1000097.

15. Parmar MK, Torri V, Stewart L. Extracting summary statistics to perform meta-analyses of the published literature for survival endpoints. Stat Med. 1998;17:2815-34.

16. Tierney JF, Stewart LA, Ghersi D, Burdett S, Sydes MR. Practical methods for incorporating summary time-to-event data into meta-analysis. Trials. 2007;8:16.

17. Higgins JP, Altman DG, Gøtzsche PC, Jüni P, Moher D, Oxman AD, Savovic J, Schulz KF, Weeks L, Sterne JA. The Cochrane Collaboration's tool for assessing risk of bias in randomised trials. BMJ. 2011;343:d5928.

18. Begg CB, Mazumdar M. Operating characteristics of a rank correlation test for publication bias. Biometrics. 1994;50:1088-101.

19. Egger M, Davey SG, Schneider M, Minder C. Bias in meta-analysis detected by a simple, graphical test. BMJ. 1997;315:629-34.

20. Pan H, Gray R, Braybrooke J, Davies C, Taylor C, McGale P, Peto R, Pritchard KI, Bergh J, Dowsett M, Hayes DF. 20-year risks of breast-cancer recurrence after stopping endocrine therapy at 5 years. N Engl J Med. 2017;377:1836-46.

21. Saphner T, Tormey DC, Gray R. Annual hazard rates of recurrence for breast cancer after primary therapy. J Clin Oncol. 1996;14:2738-46.

22. Coombes RC, Kilburn LS, Snowdon CF, Paridaens R, Coleman RE, Jones SE, Jassem J, Van de Velde CJ, Delozier T, Alvarez I, Del ML, Ortmann O, Diedrich K, Coates AS, Bajetta E, Holmberg SB, Dodwell D, Mickiewicz E, Andersen J, Lønning PE, Cocconi G, Forbes J, Castiglione M, Stuart N, Stewart A, Fallowfield LJ, Bertelli G, Hall E, Bogle RG, Carpentieri M, Colajori E, Subar M, Ireland E, Bliss JM. Survival and safety of exemestane versus tamoxifen after 2-3 years' tamoxifen treatment (Intergroup Exemestane Study): a randomised controlled trial. Lancet. 2007:369:559-70.

23. Early Breast Cancer Trialists' Collaborative Group (EBCTCG). Aromatase inhibitors versus tamoxifen in early breast cancer: patient-level meta-analysis of the randomised trials. Lancet. 2015;386:1341-52.

24. Fisher B, Redmond C, Fisher ER, Caplan R. Relative worth of estrogen or progesterone receptor and pathologic characteristics of differentiation as indicators of prognosis in node negative breast cancer patients: findings from National Surgical Adjuvant Breast and Bowel Project Protocol B-06. J Clin Oncol. 1988;6:1076-87.

25. Davies C, Godwin J, Gray R, Clarke M, Cutter D, Darby S, McGale P, Pan HC Taylor C, Wang YC, Dowsett M, Ingle J, Peto R. Relevance of breast cancer hormone receptors and other factors to the efficacy of adjuvant tamoxifen: patient-level meta-analysis of randomised trials. Lancet. 2011;378:771-84.

26. Song F, Zhang J, Li S, Wu J, Jin T, Qin J, Wang Y, Wang M, Xu J. ER-positive breast cancer patients with more than three positive nodes or grade 3 tumors are at high risk of late recurrence after 5-year adjuvant endocrine therapy. Onco Targets Ther. 2017;10:4859-67.

27. Barron Tl, Connolly R, Bennett K, Feely J, Kennedy MJ. Early discontinuation of tamoxifen: a lesson for oncologists. Cancer. 2007;109:832-9.

28. Chlebowski RT, Geller ML. Adherence to endocrine therapy for breast cancer. Oncology. 2006;71:1-9.

\section{Ready to submit your research? Choose BMC and benefit from}

- fast, convenient online submission

- thorough peer review by experienced researchers in your field

- rapid publication on acceptance

- support for research data, including large and complex data types

- gold Open Access which fosters wider collaboration and increased citations

- maximum visibility for your research: over $100 \mathrm{M}$ website views per year

At BMC, research is always in progress.

Learn more biomedcentral.com/submissions 